\title{
Dari Nuktah Menuju Nobel Sastra: Menyimak Najib Mahfuz Berkisah
}

\author{
Novriantoni Kaharudin \\ novrikahar@gmail.com
}

\begin{abstract}
Abstrak
Najib Mahfuz adalah orang yang lihai bermain lelucon atau anekdot. Plot kisahnya bahkan tidak selalu progresif, tapi terkadang juga regresif dan mundur ke belakang, terutama dalam bentuk gumaman dan suara batin tokoh-tokohnya. Salah satu ciri khas dari karya-karya Mahfuz adalah kerencaman alias kedetilan, kerumitan, dan kompleksitas watak tokoh-tokohnya. Trilogi Kairo adalah novel tiga jilid yang berjumlah sekitar 1500 halaman, yang merupakan potret dari kehidupan masyarakat Mesir dalam tiga zaman: masyarakat tradisional, masa peralihan dan kehidupan masyarakat modern. Orang yang membaca novel Mahfuz secara tuntas akan dibawa untuk mengarungi seluk-beluk peri kehidupan masyarakat Mesir yang tidak selalu mudah ditembus.
\end{abstract}

Keywords: Nuktah, novel, suara batin, realisme, citra perempuan, subtil.

Novriantoni Kaharudin adalah alumnus Universitas Al-Azhar, Kairo, Mesir (S1) dan Master Sosiologi di Universitas Indonesia. Ia telah menerjemahkan beberapa buku berbahasa Arab dan sempat mengajar di Universitas Paramadina. Kini ia bergiat di sebuah organisasi kemanusiaan dan mulai menerjemahkan karya-karya sastra Arab.

“You can't understand Egypt without Mahfouz-without his characters, with whom every reader, Arab or not, can identify." —Tahar Ben Jelloun

"[His work] has to do with the plight of humanity as a whole. He has presented it from the local angle, but it's not really local at all. It's a kind of microcosm of the whole world, a little image of the fate of man." - Fatma Moussa 


\section{Pendahuluan}

Saya bukanlah orang yang cukup betah berlama-lama mendengarkan orang berkisah. Apalagi jika pengisah kurang pandai mengolah apa yang dikisahkannya. Karena itulah, saya tidak terlalu kuat membaca novel. Jumlah novel yang sempat saya khatamkan membacanya mungkin bisa dihitung jari-jari. Tapi Ketika ditantang seorang kawan Malaysia untuk menerjemahkan novel Najib Mahfuz dari bahasa Arab ke bahasa Melayu - tepatnya bahasa Melayu saya yang sudah keindonesia-indonesiaan, bukan murni Melayu Malaysia - saya tak dapat berpaling. Saya tidak hanya tahan menerjemahkan kata demi kata dari novel Bainal Qashrain (sebuah nama tempat, tapi boleh juga diterjemahkan menjadi Dua Mahligai) sepanjang 584 halaman itu selama enam bulan, tapi juga sangat bergairah.

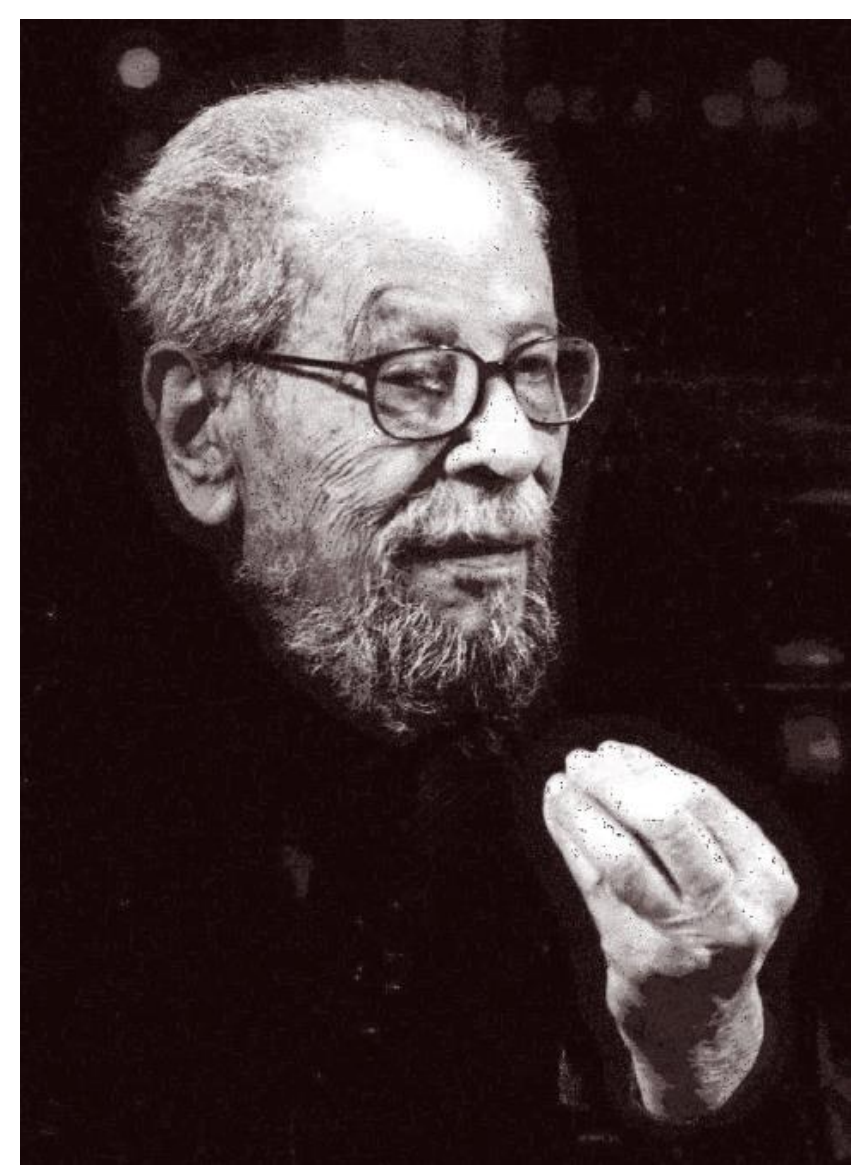

Najib Mahfuz. 
Selama menjalani masa-masa pandemi, saya menerjemahkan bagian pertama dari trilogi peraih Nobel Sastra 1988 asal Mesir itu, sejak Maret sampai akhir Agustus 2021. Selama enam bulan itu pulalah saya sanggup dan betah membaca, menelaah, mengalihbahasakan lika-liku dan detil-detil kisah yang didedahkan Mahfuz di dalam karya agungnya tentang kehidupan sosial politik kebudayaan masyarakat Mesir itu. Apa rahasianya? Selain karena sudah berkomitmen untuk menyelesaikannya tepat waktu kepada kawan yang memberikan amanah, saya juga tidak merasa jemu bahkan selalu penasaran mengikuti kelanjutan kisah-kisahnya dari bab ke bab. Selama masa penerjemahan, saya memang nyaris tak punya waktu untuk membaca hal-hal terkait Mahfuz dan hanya berfokus untuk penerjemahan agar tepat waktu. Setelah selesai menerjemahkan, barulah saya membaca berbagai buku yang mengulas sastrawan agung ini, baik biografi mau ulasan dan kritikan atas karya-karyanya.

Dari situlah saya baru menemukan bahwa Mahfuz mempunyai bakat alamiah dalam berkisah. Bakat itu dia tempa dari tongkrongannya di berbagai kafe di kota Kairo. Ada satu babak dari buku kritikus sastra bernama Raja al-Naqqasy yang mengisahkan bahwa Mahfuz adalah orang yang paling lihai bermain nuktah. Nuktah secara kebahasaaan berarti lelucon atau anekdot. Orang Mesir pada umumnya sangat menggandrungi dan menikmati nuktah. Kultur nuktah ini mirip dengan kultur humor di kalangan warga Nahdlatul Ulama di Indonesia. Orang melakukan jual beli nuktah dari satu tongkrongan ke tongkrongan lainnya. Seseorang yang pandai dan lihai menuturkan nuktah biasanya akan menjadi bintang dalam sebuah forum. Dan menurut Naqqasy, Mahfuz bukan hanya pandai dan lihai dalam menuturkan nuktah, bahkan mampu mengalahkan kawankawan satu tongkrongannya dalam berbalas nuktah. Mahfuz misalnya mampu membalas satu nuktah dengan dua puluh nuktah secara beruntun dan tanpa henti, sehingga lawannya dalam berbalas nuktah akan menyerah kalah.

\section{Dari Nuktah Menuju Novel Sastra}

Dari apa yang dikisahkan Raja al-Naqqasy di atas, saya baru mengerti kenapa saya mampu bertahan sampai tamat menerjemahkan novel yang sangat tebal itu. Saban kali selesai menerjemahkan satu bab seraya terseyum membayangkan kandungan kisahnya, saya terpicu dan terpacu untuk melanjutkan ke bab selanjutnya demi menyimak kisah 
lanjutannya. Novel Mahfuz yang saya terjemahkan ini memang merupakan satu kesatuan kisah secara keseluruhan, tapi tiap-tiap bab mengandung kisah tersendiri yang terpisah sekaligus tersambung dengan kisah sebelum dan sesudahnya. Plot kisahnya bahkan tidak selalu progresif, tapi terkadang juga regresif dan mundur ke belakang, terutama dalam bentuk gumaman dan suara batin tokoh-tokohnya.

Inilah bagian yang tersulit dalam proses penerjemahan karena menurut Al-Mustaqeem Mahmod Radhi, kawan Malaysia yang mengamanatkan saya untuk menerjemahkan novel ini, salah satu ciri khas dari karya-karya Mahfuz adalah kerencaman alias kedetilan, kerumitan, dan kompleksitas watak tokoh-tokohnya. Situasi psikologis dan suara batin tokoh-tokohnya seringkali masuk dan menyela ke dalam batang tubuh kisah. Bila kita - terutama penerjemah — tidak cermat dan teliti dalam memperhatikan dan membedakan apa yang benar-benar dikatakan sang tokoh dan apa yang hanya terpendam dalam sanubarinya dan tak sempat atau tidak jadi dia ungkapkan ke dalam dialog, maka kisahnya akan menjadi rancu. Itulah salah satu tantangan terberat dalam menerjemahkan karya Mahfuz sejauh yang saya alami.

Tapi Mahfuz memang bukan penulis amatiran. Umumnya penulis Arab sangat senang berpanjang-panjang dan berbelit-belit dalam menurutkan sesuatu. Dalam istilah Arab, inilah yang disebut gaya ithnab. Mahfuz sedikit banyak masih mengidap persoalan itu dalam kadar yang dapat dimaklumi, terutama ketika menyuarakan suara batin para tokohnya. Tapi secara umum, beberapa pengulangan yang berupa monolog suara batin tokoh-tokohnya masih dapat dinikmati karena keahlian Mahfuz dalam meramu dan membumbuinya dengan kejadian-kejadian unik yang kadang tak terbayangkan oleh kita.

Namun harus diakui pula, bukan hanya bakat alami yang membuat Mahfuz mampu berkisah sedemikian panjang dan mengesankan. Trilogi Kairo adalah novel tiga jilid yang berjumlah sekitar 1500 halaman. Selain Bainal Qashrain (Dua Mahligai) yang menjadi bagian pertamanya, masih ada Qashrus Syauq (masih nama tempat, tapi dapat diterjemahkan secara literal sebagai Istana Kerinduan) dan al-Sukkariyah (nama tempat 
yang dapat diterjemahkan sebagai Jalan al-Sukkariyah). Ketiga jilid novel ini merupakan potret dari kehidupan masyarakat Mesir dalam tiga zaman: masyarakat tradisional, masa peralihan dan kehidupan masyarakat modern. Kemampuan Mahfuz dalam memotret semangat zaman dan menyampaikan suara batin tiap-tiap zaman dan membingkai kisah-kisahnya tidaklah semata-mata karena ditempa bakat alami. Menurut brosur yang dikeluarkan American University in Cairo (2011), Mahfuz adalah seorang pembaca karya-karya sastra agung dunia semacam karya-karya Shakespeare, Conrad, Melville, Flaubert, Stendhal, Tolstoy, Proust, O’Neill, Shaw, Ibsen, dan Stindberg, baik dalam bahasa Inggris maupun bahasa Perancis.

Dari bacaannya yang luas sejak menjadi mahasiswa filsafat di Universitas Raja Fuad-1 (cikal bakal Universitas Kairo saat ini), kita tahu bahwa dia telah menejelajahi berbagai khazanah sastra dunia. Dari wawasan dunia global itulah dia kemungkinan mampu keluar dari kecenderungan novel Arab sebelumnya yang cenderung mengandung tendensi pemikiran dan keinginan untuk mengubah dunia. Lepas dari kungkungan zamannya, Mahfuz justru menjejakkan novelnya dari kisah kehidupan dan pergumulan hidup sehari-hari masyarakat Mesir yang bergelut dengan zamannya. Dia sendiri mengakui bahwa novel-novelnya memang beraliran waqiiyyah alias realisme dalam artian berkisah tentang orang-orang, tempat-tempat, peristiwa-peristiwa, persepsipersepsi, impian-impian, dan kekecewaan-kekecewaan yang dialami tokoh-tokohnya. Pembacaan secara menyeluruh terhadap karya-karya Mahfuz akan memberikan kita kesan dan pesan yang utuh tentang apa yang ingin disampaikan penulisnya. Namun kesan dan pesan itu tidaklah dia khotbahkan, paksakan dan atau menangkan di dalam batang tubuh kisahnya. Pesannya sangat halus dan tersamar dan hanya dapat kita tangkap jika kita membaca keseluruhan isinya.

Sebagai contoh, salah satu ulasan yang apik dan menyeluruh tentang novel Mahfuz, terutama trilogi Kairo, adalah apa yang dikerjakan Fauziah al-Asymawi. Fauziah menelaah gambaran tentang perempuan dari zaman ke zaman di dalam novel-novel Mahfuz. Dalam buku bahasa Arab yang diangkat dari disertasinya yang diterjemahkan dari bahasa Perancis itu, al-Mar'ah fi Adabi Najib Mahfuz (Perempuan dalam Sastra Naguib Mahfuz, terbit tahun 1985, tiga tahun sebelum Mahfuz menerima Nobel Sastra), 
Fauziah berhasil memberikan memotret gambaran tentang citra perempuan dalam berbagai babak sejarah masyarakat Mesir. Menurut Fauziah, tokoh perempuan adalah bagian sentral dan terpenting dari sastra Mahfuz dan boleh dikatakan bahwa Mahfuz benar-benar menjadikan perempuan sebagai cermin untuk memantulkan gambaran tentang perkembangan adat istiadat dan kebudayaan masyarakat Mesir pada zamannya. Gambaran tentang perempuan itu terlihat dari sosok-sosok seperti Amina, Khadija, Aisha, dan anak cucu mereka dalam tiga generasi dan bagaimana mereka menyikapi berbagai perkembangan sosial politik kebudayaan dan tantangan-tantangan pada zamannya.

Orang yang membaca novel Mahfuz secara tuntas akan dibawa untuk mengarungi seluk-beluk peri kehidupan masyarakat Mesir yang tidak selalu mudah ditembus oleh orang yang hanya bergaul sepintas lalu dengan mereka. Ketika masih kuliah di Mesir, saya tidak terlalu paham betapa pentingnya jendela dan loteng dalam hubungan lakilaki dan perempuan dalam masyarakat Mesir. Tapi setelah membaca Mahfuz, saya jadi senyum-senyum sendiri karena beberapa fragmen dalam kisah yang ditampilkan Mahfuz itu pernah saya saksikan tanpa memahami maknanya secara mendalam. Karena detil-detil subtil yang memberikan kita pemahaman tentang suara lahir maupun batin masyarakat Mesir itu, tak heran kalau panitia Nobel Sastra dalam pernyataan resmi mereka menjuluki Mahfuz sebagai juru bicara prosa Arab yang tidak terkalahkan. Melalui karya-karyanya, baik novel atau pun cerita pendek, (Mahfuz) telah mencapai standar kesempurnaan internasional sebagai sintesis dari tradisi Arab klasik, inspirasi Eropa dan keterampilan pribadi. Lebih jauh, panitia Novel menekankan alasan pemilihan Mahfuz sebagai pemenang Novel Sastra tahun 1988 sebagai berikut:

Dear Mr. Mahfouz,

Your rich and complex work invites us to reconsider the fundamental things in life. Themes like the nature of time and love, society and norms, knowledge and faith recur in a variety of situations and are presented in thought-provoking, evocative, and clearly daring ways. And the poetic quality of your prose can be felt across the language barrier. In the prize citation you are credited with the forming of an Arabian narrative 
art that applies to all mankind. On behalf of the Swedish Academy, I congratulate you on your eminent literary accomplishments. And now, may I ask you, Miss Om Kalsoum Naguib Mahfouz, and you, Miss Fatma Naguib Mahfouz, to step forward to receive from the hands of His Majesty the King, on behalf of your father Naguib Mahfouz, the Nobel Prize in Literature 1988.

(https://www.nobelprize.org/prizes/literature/1988/ceremony-speech/)

\section{Memahami Masyarakat Mesir Lewat Tokoh-Tokoh Mahfuz}

Dalam sebuah opini di New York Times, novelis Maroko bernama Tahar Ben Jelloun mengatakan bahwa Mahfouz benar-benar jendela untuk mengenal seluk beluk masyarakat Mesir. "You can't understand Egypt without Mr. Mahfouz — without his characters, with whom every reader, Arab or not, can identify," tegasnya. Jelloun bahkan mengatakan bahwa sampai saat ini, karya-karya Mahfuz telah membantu pembaca Barat untuk memahami dunia Arab. Bahkan lebih penting dari itu, Mahfuz telah pula ikut membantu dunia Arab untuk lebih memahami diri mereka sendiri (but perhaps even more important, he helped the Arab world understand itself).

Apa yang ditegaskan Jelloun di atas benar-benar saya rasakan ketika sedang menerjemahkan bagian pertama trilogi Mahfuz ini. Saya sempat kuliah di Mesir selama empat tahun dari tahun 1997 sampai 2001 dan sempat bargaul secara terbatas dan sepintas dengan orang-orang Mesir. Tapi saya tidak benar-benar tahu jeroan masyarakat Mesir secara mendalam. Harus saya akui, melalui karya Mahfuz yang kini sedang saya gandrungi, kita diajak untuk masuk ke dalam pekarangan bahkan kamar tidur orang Mesir, akal pikiran, kompleksitas perasaan, dan bahkan suara batin mereka. Melalui tokoh-tokoh yang ditampikkan Mahfuz, kita dapat mengerti kerumitan budaya, cara bernalar, sensitivitas perasaan, bahkan situasi batin orang Mesir dalam menghadapi peristiwa-peristiwa kecil maupun besar yang mereka hadapi. Mahfuz tidak hanya menampilkan apa yang terucap oleh tokoh-tokohnya, tapi juga apa yang terpendam di 
dalam sanubari mereka tentang suatu perkara yang kadang tidak sempat terucap namun tergambarkan sebagai narasi.

\section{Kontroversi Seputar Novel-Novel Simbolis}

Mahfuz sungguh-sungguh seorang penulis yang sangat peroduktif. Menurut hitunghitungan Rasheed El-Enany, Mahfuz telah meninggalkan tak kurang dari 50 lebih karya, baik yang berbentuk novel, cerita pendek, skenario, maupun otobiografi. ElEnany menampilkan setidaknya 35 novel, 14 kumpulan cerita pendek, dan 1 buku terjemahan tentang peradaban Mesir kuno (lihat lampiran). Sementara brosur yang dikeluarkan American University in Cairo dalam rangka peringatan seratus tahun Naguib Mahfouz (2011) mendaftarkan setidaknya 55 karya Mahfouz sejak tahun 1938 sampai 2005 ketika dia tidak lagi mampu menulis lebih dari setengah jam setelah ditikam sekelompok kaum fanatik di luar rumahnya di tahun 1994.

Penikaman terhadap Mahfuz tidak lain karena kesalahpahaman tentang novelnya yang paling kontroversial, Awlad Haratina (Anak-Anak Kampung Kami) atau yang diterjemahkan ke dalam bahasa Inggris dengan Children of Gabelawi. Di dalam kritik sastra yang dituangkan Georges Tarabichi, novel simbolik Mahfuz ini dianggap sebagai sebuah proyek ambisius untuk menuliskan ulang sejarah umat manusia sejak zaman paling azali menurut ketentuan kitab-kitab agama sampai masa kini. Di dalam novel ini, Mahfuz mengisahkan sosok Gabelawi yang punya anak keturunan yang secara konstan menampilkan pertarungan abadi umat manusia antara yang baik dan buruk, keinginan dan kerinduan untuk kembali ke taman Firdaus dan kehendak menguasai apa yang diwariskan Gabelawi. Pertarungan itu bersifat permanen dan selalu berulang dengan berbagai sosok dan tokoh yang menampilkan kekuatan-kekuatan baik maupun jahat. Mahfuz menggunakan dan memelesetkan berbagai simbol dan karakter yang terdapat dalam kisah-kisah keagamaan demi merepresentasikan pertarungan sengit di perkampungan yang dibangun Gabelawi itu. Apakah Mahfuz berhasil menuliskan ulang sejarah umat manusia itu secara sastrawi? 
Menurut Georges Tarabichi, Aulad Haratina memang ditulis dengan gaya bahasa yang konotatif, simbolik, ambigu. Namun simbol-simbol yang dipergunakan di dalamnya seperti sosok Gabelawi, Idris, Abbas, Ridwan, Jalil, Adham, Umaimah, Qadri, Humam, Jabal, Rifa'ah, Qasim, Arafah dan lain-lain), terlalu mudah diditeksi dan dipahami sebagai sosok-sosok yang dikenali kalangan keagamaan. Karena begitu sensitifnya kisah yang diutarakan Mahfuz itu, bagi Tarabichi pilihan Mahfuz hanya dua: entah menghindar dari topik-topik seperti itu, atau bertumpu kepada simbolisme radikal dan membuatnya seabstrak mungkin tanpa mudah dideteksi dan diasosiasikan dengan paham-paham yang sudah mapan di kalangan keagamaan. Menurut Tarabichi, sangat disayangkan, ambisi Mahfuz untuk menuliskan ulang sejarah umat manusia lewat Aulad Haratina dan misinya untuk mengharmonisasi hubungan antara agama dan ilmu pengetahuan sehingga menghasilkan agama yang sekular (almanat ad-din) dan ilmu yang sakral (tadyin al-ilm) tidak mendapatkan sambutan yang baik di kalangan agamawan dan menimbulkan petaka bagi dirinya. Padahal, novel tersebut bila dipahami secara benar mestinya akan menyenangkan kalangan agama dan akan sedikit mengecewakan kalangan sekular.

\section{Penutup}

Mungkin karena alasan itu, karya-karya Mahfuz yang menyinggung tentang aspekaspek keagamaan setelah Aulad Haratina dia buat seabstrak mungkin, bahkan hampirhampir menyerupai teka-teki. Tekanan sosial dan sensitivitas keagamaan telah membuat Mahfuz belajar tentang perlunya mencari cara lain dalam menyampaikan pesan lewat karya-karyanya. Namun, betapapun abstrak dan rumitnya karya Mahfuz setelah itu, kita tetap mendapatkan kisah dan cerita yang tidak biasa. Keunggulan masa kecil Mahfuz yang mampu menyampaikan nuktah di luar kepala, secara luar biasa tetap menghiasi karya-karya sastranya sehingga kita tidak akan pernah bosan mendengarnya berkisah. 


\section{Bahan Bacaan:}

1. Jamal al-Ghaithani, Najib Mahfuz Yatadtakkar (Najib Mahfud Berkisah), Beirut, Dar alMasirah, 1980.

2. Raja al-Naqqash, Fi Hubbi Najib Mahfuz (Tentang Cinta untuk Najib Mahfuz), Kairo, Dar al-Syuruq, 1995.

3. Al-Syaikh Abdul Hamid Kisyk, Kalimatuna Fi al-Raddi ala Auladi Haratina Najib Mahfuz (Pernyataan Kita untuk Menyanggah Novel Aulad Haratina Najib Mahfuz), Kairo, Kitab al-Mukhtar, 1994.

4. Ibrahim Abdul Aziz, Ana Najib Mahfud: Sirat Hayat Kamilah (Aku Najib Mahfuz: Riwayat Hidup Lengkap), Kairo, Nevro, 2006.

5. Fauziah al-Asymawi, al-Mar'ah Fi Adabi Najib Mahfuz (Perempuan dalam Sastra Najib Mahfuz), Kairo, al-Majlis al-A'la li al-Tsaqafah, 2002.

6. Muhammad Ali Salamah, Namuzaj al-Syakhsyiyyah al-Diniyyah fi Riwayati Najib Mahfuz (Contoh-Contoh Figur Agama dalam Novel Najib Mahfuz), Aleksandria, Dar alWafa, 2007.

7. Rasheed el-Enany, Naguib Mahfouz: the Pursuit of Meaning, London, Routledge, 1993

8. Naguib Mahfouz, Echoes of an Autobiography (diterjemahkan oleh Danies JohnshonDavies), New Zork: Doubleday, 1997.

9. Georges Tharabichi, Allah fi Rihlati Najib Mahfuz al-Rumziyyah (Tuhan dalam Petualangan Simbolik Najib Mahfuz), Beirut: Dar al-Thaliah, 1988 (cetakan ketiga). 10. Brochure of Mahfudz Centennial Celebration 2011, Naguib Mahfouz: 1911-2006, The American University in Cairo Press, 2011.

\section{Lampiran 1:}




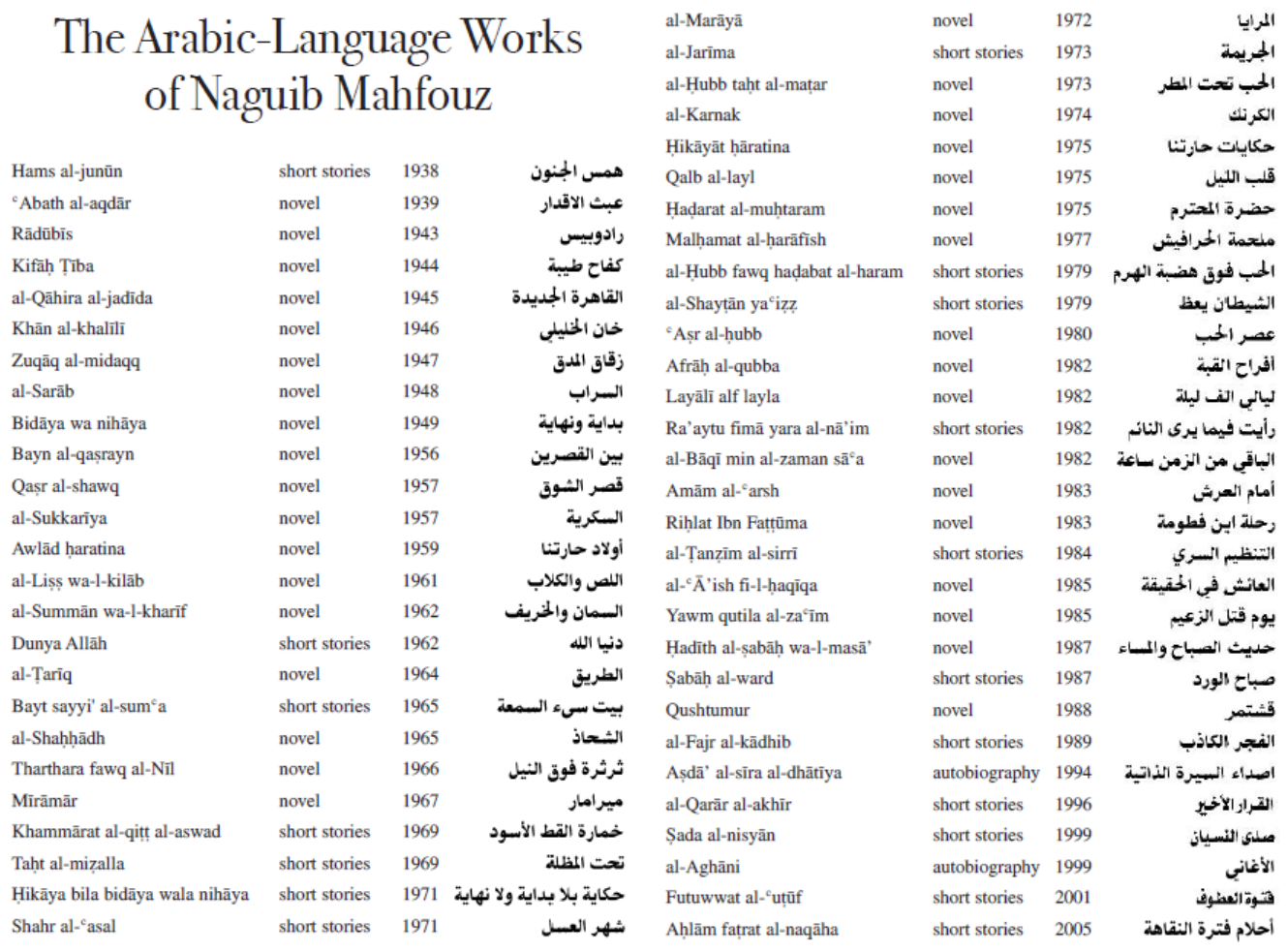

\section{Lampiran 2:}

THE NOVELS

The Game of Fates

Rhodopis

The Struggle of Thebes 1944 (n.d.)

Khan al-Khalili $1945^{* *}\{1960\}$

New Cairo 1946** (1974)

Midaq Alley ${ }^{*} \quad 1947 \quad(1972$

Mirage $\mathbf{1 9 4 8}$ (1982)

The Beginning and the End ${ }^{*} \quad 1949 \quad$ (1973)

The (Cairo) Trilogy:

Palace Walk*

Sumar Street*

Children of Gebelawi* (1967) (1972)

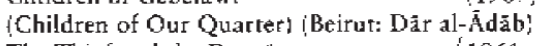

The Thief and the Dogs" "1961 (n.d.)

Autumn Quail* * 1962 (n.d.)

The 5earch * $1964 \quad$ (1965)

$1964 \quad(1965)$

The Beggat

Chatter on the Nile

Miramar $\quad 1967 \quad\{1976$

\begin{tabular}{|c|c|c|}
\hline Tharthara fawg al-Nil & Chatter on the Nile & 1966 \\
\hline Mirāmàr & Mirâmar & 1967 \\
\hline A|-Marāya & Mirrars & 1972 \\
\hline
\end{tabular}


Hubb tabt al-Matar

Al-Karnak

Hadrat al-Mubtaram

Hikāyāt Hāratinā

Qalb al-Layl

Malhamat al-Harāfish

cAssral-Hubb

Afräh al-Qubba

Layälï Alf Layla

Al-Bãqi $\min$ al-Zaman $S_{a}{ }^{c} a$

Rihlat Ibn Fattūma

Amām al-c Arsh

Yaum Qutil al-Zacim

Al- ${ }^{c} \bar{A}^{\prime}$ ish fi al-Haqiqa

Hadith al-Șabāh wa al-Masā'

Qushtumur
Love in the Rain 1973

Karnak * 1974

Respected Sir* 1975

The Fountain and the Tomb* 1975

(Tales from our Quarter) 1975

Heart of the Night $\quad 1975$

$\begin{array}{ll}\text { Epic of the Harafish } & 1980 \\ \text { The Age of Love } & 1981\end{array}$

$\begin{array}{ll}\text { The Age of Love } & 1980 \\ \text { Wedding Song* } & 1981\end{array}$

Nights of the Thousand Nights $\quad 1982$

There Only Remains One Hour 1982

The Journey of Ibn Fattouma * 1983

(referred to in this book as The Travels of Ibn Fattuma)

Before the Throne 1983

The Day the Leader was Killed* $\quad 1985$

He who Lives in the Truth 1985

Tales of Mornings and Evenings $\quad 1987$

Qushtumur 1988

\section{COLLECTED SHORT STORIES}

(Titles of collections including plays will be followed by the number of plays they contain between square brackets.)

Hams al-Junūn

Dunyā Allāh

Bayt Sayyi' al-Sumª

Khammārat al-Qitt al-Aswad

Taht al-Mazalla [S]

Hikāya bilä Bidāya walà Nihâya

Shahr al-cAsal

Al-Jarima [1]

Al-Hubb fawq Hadabat al-Haram

Al-Shaytän Yaciz [2]

Ra'ayt fímā Yarā al-Nâ'im

Al-Tanzim al-Sirri

Sabāh al-Ward

Al-Fair al-Kädhib

Whispers of Madness

God's World

A House of III Repute

The Black Cat Tavern

Under the Bus Shelter

A Tale without Beginning or End

The Honeymoon

The Crime

Love under the Pyramids

The Devil Preaches

I Saw in a Dream

The Secret Organization

Good Morning to You

The False Dawn

\section{TRANSLATIONS}

Mișt al-Qadima
Ancient Egypt

1931?**

(1988) 